\title{
Inhibition of AP-1 and MAPK signaling and activation of Nrf2/ARE pathway by quercitrin
}

\author{
MIN DING $^{1}$, JINSHUN ZHAO ${ }^{1}$, LINDA BOWMAN $^{1}$, YONGJU LU ${ }^{1}$ and XIANGLIN SHI ${ }^{2}$ \\ ${ }^{1}$ Pathology and Physiology Research Branch, Health Effects Laboratory Division, National Institute for \\ Occupational Safety and Health, Morgantown, WV 26505; ${ }^{2}$ Graduate Center for Toxicology, \\ College of Medicine, The University of Kentucky, Lexington, KY 40503, USA
}

Received July 16, 2009; Accepted September 7, 2009

DOI: 10.3892/ijo_00000475

\begin{abstract}
Quercitrin, glycosylated form of flavonoid compounds, is widely distributed in nature. Extensive studies have demonstrated that quercitrin exhibits strong antioxidant and anti-carcinogenic activities. However, the molecular mechanism is poorly understood. The present study examines the effects of quercitrin on tumor promotion in mouse JB6 cells, a validated model for screening cancer chemopreventive agents and elucidating the molecular mechanisms. Quercitrin blocked TPA-induced neoplastic transformation in JB6 $\mathrm{P}^{+}$ cells. Pretreatment of JB6 cells with quercitrin down-regulated transactivation of AP-1 and NF- $\mathrm{KB}$ induced by UVB or TPA. In the skin of AP-1-luciferase transgenic mice, topical treatment of the mouse with quercitrin markedly blocked the TPA-induced AP-1 transactivation. Further studies indicated that these inhibitory actions appear to be mediated through the inhibition of MAPKs phosphorylation, including ERKs, p38 kinase, and JNKs. In addition, quercitrin stimulated the activation of NF-E2-related factor (Nrf2) and GST AREluciferase activity. Comet assays showed that quercitrin could block DNA damage induced by UVB. To our knowledge, these results provide the first evidence that quercitrin contributes to the inhibition of neoplastic transformation by blocking activation of the MAPK pathway and stimulation of cellular protection signaling. Moreover, to our knowledge, these findings provide the first molecular basis for the anticarcinogenic action of quercitrin.
\end{abstract}

Correspondence to: Dr Min Ding, Pathology and Physiology Research Branch, Health Effects Laboratory Division, National Institute for Occupational Safety and Health, Morgantown, WV 26505, USA

E-mail: mid5@cdc.gov

Dr Xianglin Shi, Graduate Center for Toxicology, College of Medicine, The University of Kentucky, Lexington, KY 40503, USA E-mail: xshi5@uky.edu

Key words: flavonoids, antioxidant, cell signaling, cancer prevention

\section{Introduction}

Previous studies have indicated that reactive oxidative species (ROS) function as second messengers in numerous signaling pathways involved in a diverse array of biological responses ranging from transcriptional regulation, differentiation and proliferation to oncogenic transformation $(1,2)$. Increased formation of ROS can promote the development of malignancy, and the 'normal' rates of ROS generation may account for the increased risk of cancer development and neurodegenerative disorders $(3,4)$. Therefore, interventions favoring the scavenging of ROS (dietary and pharmacological antioxidants) to attenuate the oxidative stress may prevent oxidant stressassociated diseases. A report published by the American Institute for Cancer Research regarding dietary prevention of cancer indicates that $7-31 \%$ of all cancers worldwide could be reduced by diets high in fruits and vegetables (5). Thus, searching for novel natural agents and defining novel targets for chemoprevention have become an important area of investigation.

Flavonoids are components of the human diet and are widely found in vegetables and fruits (4). Flavonoids exert various biological activities, which are mainly related to their abilities to inhibit enzymes, to their antioxidant properties, and to their effects on immune responses (6). These activities may explain the beneficial effects that flavonoid intake exerts in different human pathologies, including hypertension, inflammatory conditions, and cancer (7). Quercetin is the most abundant bioflavonoid compound, which is mainly present in the glycoside form. The sugar portion bound to the aglycone portion in quercitrin increases its solubility in polar solvents and consequently improves absorption (8). Recent in vitro cell culture or in vivo animal experiment studies have demonstrated that quercitrin exhibits a scavenger and anti-oxidant role (9). Therefore, the study of the potential anti-carcinogenic activity of quercitrin has attracted the attention of researchers who intend to identify whether this compound could be an effective chemoprevention and chemotherapeutic agent. Although literature data indicate that quercitrin is a potent antioxidant, the exact mechanism(s) which underlie its protective effects is poorly understood (9).

The cellular signaling cascades mediated by transcription factors, including activator protein-1 (AP-1) and nuclear factor- $\kappa \mathrm{B}(\mathrm{NF}-\kappa \mathrm{B})$, have been shown to play pivotal roles in 
tumor initiation, promotion and progression (10). Activation of $\mathrm{AP}-1$ and/or NF- $\mathrm{KB}$ results in the expression of target genes that are involved in many disease processes, such as inflammation, neoplastic transformation, tumor progression, metastasis and angiogenesis (11). Activated AP-1 and NF- $\mathrm{KB}$ are found in many different cancer cells (12). The signal transduction pathways of AP-1 and/or NF- $\mathrm{KB}$ are known to be important molecular targets of chemo-preventive strategies (13). The components of AP-1 are activated by three distinct but parallel mitogen-activated protein kinases (MAPKs), c-jun NH2-terminal kinase (JNK), p38, and extracellular signalregulated kinases (ERKs). AP-1, NF- $\mathrm{KB}$, and associated MAPK signal transduction pathways are believed to be crucial in cell transformation and tumor promotion (14). Because of the critical role of AP-1 and NF- $\mathrm{BB}$ signaling in inflammation and carcinogenesis, they have been proposed as targets for chemo-preventive agents (13).

Nrf2, a transcription factor, has been shown to play an essential role in the antioxidant response element (ARE)mediated expression of phase 2 detoxifying enzymes and stress-inducible genes (15). Regulation of both basal and inducible expression of cytoprotective genes is mediated in part by the ARE, a cis-acting sequence found in the 5'-flanking region of genes encoding many phase 2 enzymes, including heme oxygenase-1, glutathione S-transferase (GST) A1, $\mathrm{NAD}(\mathrm{P}) \mathrm{H}$ quinone oxidoreductase (NQO1), as well as Nrf2 itself (16). The likely importance of these protective enzymes is highlighted by recent observations that Nrf2-null mice were considerably more sensitive to the tumorigenicity of benzo[a]pyrene (17) and form higher levels of DNA adducts following exposure to carcinogens (18). Thus, the induction of phase 2 gene expression is an effective strategy for achieving protection against carcinogenesis.

Ultraviolet B (UVB), as a tumor initiator, is the most frequently used photocarcinogen in animal studies (19-21). 12-O-tetradecanolyphorbol-13-acetate (TPA) is used as a promoter in skin tumor development in mice (21). Our previous studies indicate that both UVB and TPA can activate AP- 1 or $\mathrm{NF}-\kappa \mathrm{B}$ signal pathways $(22,23)$. Because of the important role of $\mathrm{AP}-1, \mathrm{NF}-\mathrm{\kappa B}$ and $\mathrm{Nrf} 2$ in carcinogenesis, the present study investigated the effect of quercitrin on UVB- or TPAinduced AP-1-MAPKs and NF- $\mathrm{kB}$ activation and Nrf2/ARE activity. Furthermore, the protective effects of quercitrin against UVB-induced DNA damage were also evaluated.

\section{Materials and methods}

Materials. Quercitrin and TPA were purchased from Sigma Aldrich (St. Louis, MO). Eagle's minimal essential medium (EMEM) and Dulbecco's modified Eagle's medium (DMEM) were obtained from BioWhittaker Biosciences (Walkersville, MD). Opti-MEM I medium was obtained from Invitrogen (Carlsbad, CA). Fetal bovine serum (FBS), trypsin, gentamicin and L-glutamine were purchased from Life Technologies, Inc. (Gaithersburg, MD). Luciferase assay kits were purchased from Promega (Madison, WI). Luciferase reporter plasmids for GSTA1 ARE were kindly provided by Drs M.K. Kwak and T.W. Kensler (Johns Hopkins University, Baltimore, MD) (24). FuGENE6 Transfection reagent was purchased from Roche Diagnostics (Mannheim, Germany). Phospho-antibody kits were purchased from Cell Signaling Technology (Beverly, MA). All other antibodies were obtained from Santa Cruz Biotechnology Co. (Santa Cruz, CA). Reagent kit for single cell gel electrophoresis assay was purchased from Trevigen (Gaithersburg, MD). Cell proliferation kit I (MTT) was obtained from Roche Applied Science (Penzberg, Germany).

Cell culture. The JB6 $\mathrm{P}^{+}$mouse epidermal cell line and JB6 cells, stably transfected with either AP-1-luciferase or NF-кBluciferase reporter plasmid (25), were cultured in EMEM containing 5\% FBS, 2 mM L-glutamine, and 100 units $/ \mathrm{ml}$ penicillin and $0.1 \mathrm{mg} / \mathrm{ml}$ streptomycin. The cells were grown at $37^{\circ} \mathrm{C}$ in a $5 \% \mathrm{CO}_{2}$ atmosphere and $80 \%$ humidity.

Total antioxidant capacity assay. The total antioxidant capacity assay was carried out as described previously in JB6 cells (26). Briefly, the total antioxidant capacity of quercitrin was determined using an ABTS (2, 2'-azino-diethylbenzthiazoline sulfonate) test set (Randox Laboratories Ltd., UK). The principle of the assay depends on production of the radical cation ABTS+ in incubation medium containing the substrates $\left(\mathrm{H}_{2} \mathrm{O}_{2}\right.$ and peroxidase), which is a blue-green color and can be detected at $600 \mathrm{~nm}$. The suppression degree of this color production caused by the antioxidants in the sample is proportional to their concentrations. The assays were calibrated against standards and expressed as micromoles per liter.

Comet assay. Comet assay (single-cell gel electrophoresis) was carried out according to the procedure of Sinle et al $(27,28)$. Briefly, JB6 cells $\left(5 \times 10^{4}\right)$ were seeded in 24 -well plates. Six hours later, cells were starved by incubation in $0.1 \%$ FBS medium for $12 \mathrm{~h}$. The cells were pretreated with various concentrations of quercitrin for $1 \mathrm{~h}$ and then exposed to UVB $\left(4 \mathrm{~kJ} / \mathrm{m}^{2}\right)$ irradiation. All the steps were conducted in dimmed light to prevent additional DNA damage. Comets were visualized using a fluorescence microscope (Olympus, AX70) with an image capture system (SamplePCI, Compix Inc., Cranberry Township, PA). For each sample, 50 cells were scored at magnification, $\mathrm{x} 400$. The length of the comet tail, which indicates DNA migration, from the digitized images was determined as the distance between edge of head and end of tail using an image analysis system (Optimas 6.51, Media Cybernetics Inc., Silver Spring, MD) (29).

Cytotoxicity assay. Effects of quercitrin on cell proliferation were evaluated using Electric Cell-substrate Impedance Sensor (ECIS) Model 1600R (Applied BioPhysics, Troy, NY). The ECIS assay has been used for continuous measurement of cell micromotion, attachment, spreading and growth. The JB6 cells $\left(10^{4}\right)$ were suspended in $400 \mu 1$ of EMEM with or without quercitrin and seeded on electrodes. The cells were equilibrated in the incubator for $15 \mathrm{~min}$. The rate of cell proliferation on the microelectrode was monitored for $72 \mathrm{~h}$ as real-time changes in resistance.

Cytotoxicity of quercitrin on JB6 cells was assessed with an MTT assay kit following the manufacturer's instructions. Cells were plated at a density of $10^{4}$ cells/well in a 96-well plate. Cells were cultured, differentiated, and treated with or without quercitrin. Following $72 \mathrm{~h}$ incubation, $10 \mu \mathrm{l}$ MTT labeling reagent was added in each well and the plates were 
further incubated for $4 \mathrm{~h}$. Then $100 \mu \mathrm{l}$ solubilization solution was added, and the plate was incubated overnight at $37^{\circ} \mathrm{C}$. The optical density (OD) of the wells was measured at a wavelength of $590 \mathrm{~nm}$ with reference of $650 \mathrm{~nm}$ using an ELISA plate reader. Results were calibrated with OD measured without cells in culture.

Assay of AP-1 and $N F-\kappa B$ activity in vitro and in vivo. A confluent monolayer of JB6 cells, stably transfected with either AP-1-luciferase or a NF-кB-luciferase reporter plasmid, was trypsinized, and $2.5 \times 10^{4}$ viable cells suspended in $0.5 \mathrm{ml}$ of EMEM supplemented with 5\% FBS were seeded into each well of a 48-well plate. Plates were incubated overnight at $37^{\circ} \mathrm{C}$ in a humidified atmosphere of $5 \% \mathrm{CO}_{2}$. The medium was then switched to $0.1 \%$ FBS EMEM, and cells were cultured for $24 \mathrm{~h}$ to minimize basal activity of AP-1 or NF-kB. The cells were pretreated with or without quercitrin for $1 \mathrm{~h}$ and then exposed to TPA (20 ng/ml) or UVB irradiation $\left(4 \mathrm{~kJ} / \mathrm{m}^{2}\right)$. The cells were extracted with $150 \mu \mathrm{l}$ of $1 \mathrm{X}$ lysis buffer provided in the luciferase assay kit by the manufacturer. Luciferase activity was measured as described previously (22). The results are presented as relative AP-1 or NF- $\mathrm{KB}$ activity compared to untreated control.

The in vivo effect of quercitrin on the AP-1 activity was explored by using AP-1-luciferase reporter transgenic mice (30,31). The mice were bred and housed in the West Virginia University (WVU) Animal Facility. The animal protocols were approved by WVU-ACUC. Both male and female mice (6-9 weeks old) were used. Dorsal skin of the mice was shaved, and 2 days later a single dose of $1.34 \mathrm{mg}$ quercitrin dissolved in $300 \mu \mathrm{l}$ of acetone was applied by dermal exposure in the mice. One hour after treatment with quercitrin, the mice (except the negative control group) were treated by dermal exposure to $10.51 \mu \mathrm{g}$ of TPA dissolved in $300 \mu \mathrm{l}$ acetone. The negative control mice were treated with acetone only. The luciferase activities were detected by using dorsal skin punch biopsy samples as described previously $(30,31)$. Briefly, the skin tissues were obtained by a $1.5-\mathrm{mm}$ Biopsy Punch (Acuderm Inc., FT. Lauderdale, FL) after exposure. The tissues were lysed in $2 \mathrm{X}$ lysis buffer (from the luciferase assay kit) at $4^{\circ} \mathrm{C}$ for $12 \mathrm{~h}$. Luciferase activity of $\mathrm{AP}-1$ was measured.

Immunocytochemical staining. Cells were grown on sterilized cover slips until 60-80\% confluent and then pretreated with quercitrin. Cells were fixed with $4 \%$ paraformaldehyde in PBS, permeabilized with $0.5 \%$ Triton X-100/PBS for $30 \mathrm{~min}$, and blocked with $3 \%$ bovine serum albumin in PBS for $1 \mathrm{~h}$ at $37^{\circ} \mathrm{C}$. The cells were then incubated with NF-кB anti-p65 antibody (sc-372, 1:1000) or anti-AP-1 anti-c-jun antibody (sc-1694, 1:1000) at $37^{\circ} \mathrm{C}$ for $3 \mathrm{~h}$. After washing with PBS, Alexa Fluor 488 secondary antibody was used. Fluorescence images were acquired with a confocal laser scanning microscope (Zeiss LSM 510, Thornwood, NY).

Western blot and protein kinase phosphorylation assay. Briefly, JB6 cells were plated onto a 6-well plate. The cultures were grown $24 \mathrm{~h}$ and then starved in $0.1 \%$ FBS EMEM overnight. Cells were pretreated with different concentrations of quercitrin for $1 \mathrm{~h}$ and then were exposed to UVB $\left(4 \mathrm{~kJ} / \mathrm{m}^{2}\right.$, for $\left.14 \mathrm{~min}\right)$ irradiation or TPA $(20 \mathrm{ng} / \mathrm{ml})$. After $12 \mathrm{~h}$ incubation, the protein was extracted from the cells with $1 \mathrm{X}$ SDS sample buffer. Immunoblots for phosphorylation of JNKs, p38, and ERKs were carried out as described in the protocol of the manufacturer. Nonphospho-specific antibodies against JNKs, p38 and ERKs proteins provided in the assay kits were used to normalize the phosphorylation assay, using the same transferred membrane blot (22).

Nuclear translocation assay of Nrf2. Nuclear extracts from JB6 cells were prepared as described previously (32). Briefly, cells were treated in the presence or absence of quercitrin. After treatments, cells were harvested and suspended in hypotonic buffer A [10 mM HEPES, pH 7.6, $10 \mathrm{mM} \mathrm{KCl,}$ $0.1 \mathrm{mM}$ EDTA, $1 \mathrm{mM}$ dithiothreitol (DTT), $0.5 \mathrm{mM}$ PMSF] for $10 \mathrm{~min}$ on ice and then vortexed for $10 \mathrm{sec}$. Nuclei were pelleted by centrifugation at $12,000 \mathrm{x}$ g for $20 \mathrm{sec}$ and were resuspended in buffer $\mathrm{C}$ (20 mM HEPES, pH 7.6, 25\% glycerol, $0.4 \mathrm{M} \mathrm{NaCl}, 1 \mathrm{mM}$ EDTA, $1 \mathrm{mM}$ DTT, $0.5 \mathrm{mM}$ phenylmethylsulfonyl fluoride) for $30 \mathrm{~min}$ on ice. The supernatants containing nuclear proteins were collected after centrifugation at $12,000 \mathrm{x} g$ for $2 \mathrm{~min}$. Nrf2 proteins in either nuclear or in whole cell lysate were detected by Western blot analysis. Anti-actin antibody was used as a loading control.

Measurement of GST Al ARE-luciferase activity. A DNA sequence containing the GST A1 ARE (-833 to -533 from the start codon) was inserted into a luciferase reporter vector as described previously (24). JB6 cells were plated on a 24-well plate at a density of 50-60\% confluence. The cells were grown overnight, and the transfection complex containing $0.5 \mu \mathrm{g}$ plasmid DNA in Opti-MEM I medium was added to each well. Twenty-four hours after transfection, quercitrin was added to cells and then incubated for another $24 \mathrm{~h}$. Luciferase activity was measured using the luciferase assay kit as described above.

Enzyme activity assay. Total GST activity of the cytosolic extracts was measured spectrophotometrically as described previously using chloro-2,4-dinitrobenzene (CDNB) as the substrate (33). JB6 cells seeded in a 24-well plate were incubated with quercitrin for $24 \mathrm{~h}$. The cells were washed and then lysed with $200 \mu \mathrm{l}$ lysis buffer $(0.25 \mathrm{M}$ sucrose, $10 \mathrm{mM}$ Tris-HCl, pH 7.5, 1 mM EDTA, $0.5 \mathrm{mM}$ DTT, $0.5 \mathrm{mM}$ PMSF and 1\% Triton X-100) for $30 \mathrm{~min}$. Cytosolic fractions were prepared by centrifugation at $12,000 \mathrm{x}$ g for $10 \mathrm{~min}$. Assays were conducted in a thermostate compartment at $25^{\circ} \mathrm{C}$. Cytosolic protein $(45 \mu \mathrm{g})$ was added to $800 \mu \mathrm{l}$ of reaction mixture containing $100 \mathrm{mM} \mathrm{KH}_{2} \mathrm{PO}_{4}(\mathrm{pH}$ 6.5) and $1 \mathrm{mM}$ glutathione. The reaction was initiated by adding $1 \mathrm{mM}$ CDNB, and the formation of thioether after 5 min was measured at $340 \mathrm{~nm}$. Total enzymatic activity of GST was expressed as $\mathrm{nmol} / \mathrm{min} / \mathrm{mg}$ protein.

For the NQO1 detection, the cells were grown in a 96-well plate, treated with various concentrations of quercitrin, and lysed by $0.8 \%$ digitonin. The reaction solution [ $25 \mathrm{mM}$ Tris$\mathrm{HCl}$ (pH 7.4), $0.06 \%$ bovine serum albumin, $5 \mu \mathrm{M}$ FAD, $1 \mathrm{mM}$ glucose 6-phosphate, $30 \mu \mathrm{M}$ NADP, 300 units of glucose-6phosphate dehydrogenase, $725 \mu \mathrm{M}$ 3-(4,5-dimethylthiazol-2yl)-2,5-diphenyltetrazolium bromide, and $50 \mu \mathrm{M}$ menadione] 
A

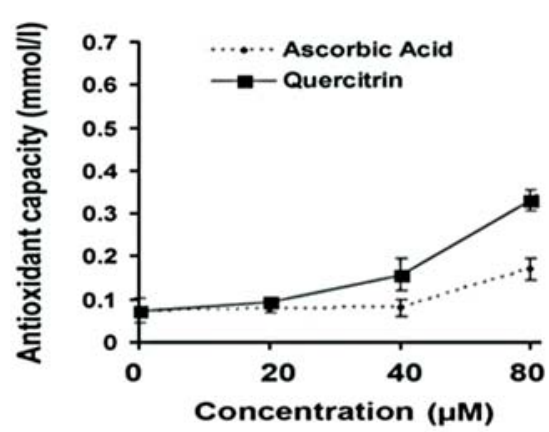

B

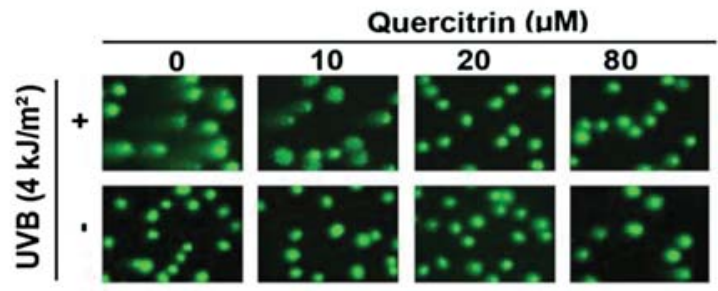

C

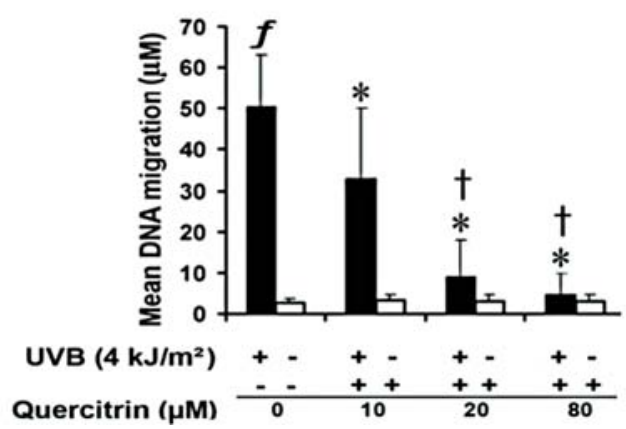

Figure 1. Antioxidant property of quercitrin. (A) The total antioxidant capacity of quercitrin was measured using an ABTS assay. Data shown as total antioxidant capacity are means \pm SE of three independent assays. Quercitrin elicited a similar antioxidant activity compared to ascorbic acid over the same concentration range analyzed using pair-wise t-test $(\mathrm{p}>0.05)$. Comet assay was carried out to detect the antioxidant action of quercitrin on the DNA damage induced by UVB irradiation in JB6 cells. (B) Representative images of cell comet were captured using microscopy at magnification, $x 400$. The lengths of comet tails from digitized images were determined by measuring the distance between edge of head and end of tail, and expressed as DNA migration in microns. (C) Fifty cells were scored for each sample. Data were analyzed using Kruskal-Wallis One Way Analysis of Variance on Ranks (all Pair-wise Multiple Comparison Procedures, Tukey Test). *Significant decrease of length of the comet tails when quercitrin was added compared to UVB radiation treatment alone $(\mathrm{p} \leq 0.05)$. ${ }^{f}$ Significant increase of length of the comet tails compared to negative control. Significant decrease of length of the comet tails compared to treatment group of $\mathrm{UVB}+10 \mu \mathrm{M}$ quercitrin.

was added into the wells, and the reduced 3-(4,5-dimethylthiazol-2-yl)-2,5-diphenyltetrazolium bromide was measured at $610 \mathrm{~nm}$. NQO1 induction by quercitrin was expressed as ratios of treated over vehicle control.

Anchorage-independent transformation assay. The effect of quercitrin on TPA-induced cell anchorage-independent transformation was evaluated in JB6 $\mathrm{P}^{+}$cells using the soft agar assay as described previously (26). The cells $\left(10^{4}\right)$ were exposed to TPA $(20 \mathrm{ng} / \mathrm{ml})$ in the presence or absence of different concentrations of quercitrin, in $1 \mathrm{ml}$ of $0.33 \%$ basal medium Eagle agar containing 15\% FBS over $3.5 \mathrm{ml}$ of $0.5 \%$
A

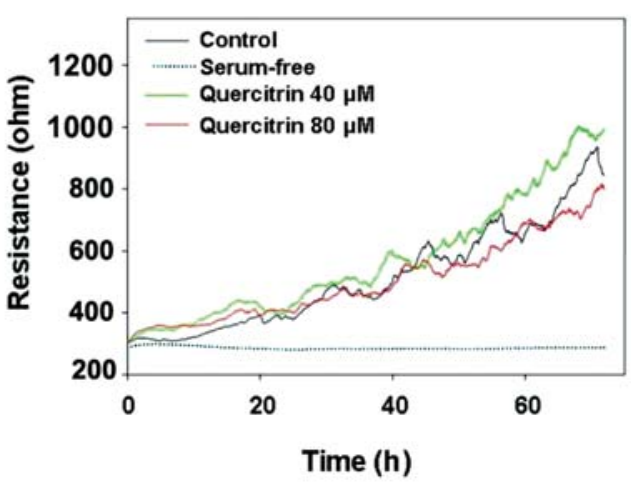

B

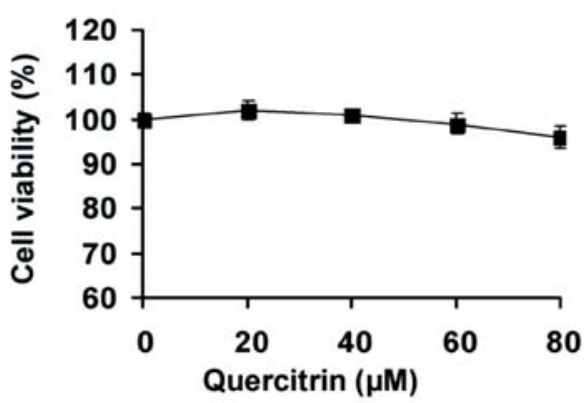

Figure 2. Effect of quercitrin on cell proliferation of A549 and JB6 cells detected by ECIS and MTT assays. (A) A549 cells were monitored in the electrode array wells under the incubation conditions of no treatment, serum free medium, 40 and $80 \mu \mathrm{M}$ quercitrin for $72 \mathrm{~h}$ as real-time changes in resistance. Data shown are representative of two independent experiments. (B) The influence of quercitrin on JB6 cell proliferation was evaluated by the MTT assay following $72 \mathrm{~h}$ incubation with various concentrations of quercitrin $(0,20,40,60$ and $80 \mu \mathrm{M})$.

agar containing $15 \%$ FBS EMEM. The cultures were maintained in a $37^{\circ} \mathrm{C}, 5 \% \mathrm{CO}_{2}$ incubator for 14 days, and the anchorage-independent colonies were counted as described previously (34).

Statistical analysis. Data are presented as means \pm SE of number of experiments/samples as noted in the figure legends. All data were analyzed using SigmaPlot 9.0 software. Significance was set at $\mathrm{p} \leq 0.05$.

\section{Results}

Total antioxidant capacity of quercitrin. Fig. 1A shows quercitrin displayed a similar antioxidant activity compared to ascorbic acid over the same concentration range ( $\mathrm{p}>0.05)$, suggesting that quercitrin can effectively scavenge ROS as well as ascorbic acid.

Inhibition of quercitrin on UVB-induced DNA damage. To investigate the protective action of quercitrin on UVB-induced oxidative damage, the comet assay was carried out in JB6 cells. Cultures of JB6 cells were pretreated with or without quercitrin at a concentration range of 10,20 and $80 \mu \mathrm{M}$ for $30 \mathrm{~min}$. Then, cells were subjected to exposure of UVB $\left(4 \mathrm{~kJ} / \mathrm{m}^{2}\right)$ irradiation for $14 \mathrm{~min}$. At $1 \mathrm{~h}$ following irradiation, cells were prepared as described in Materials and methods. Comet tails were monitored using a fluorescence microscope 
A

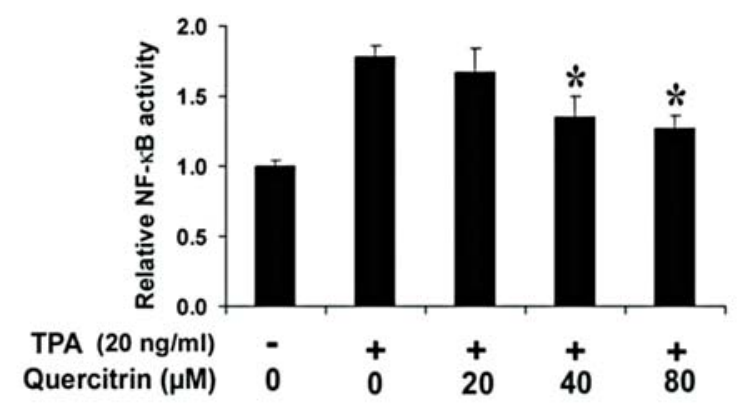

C

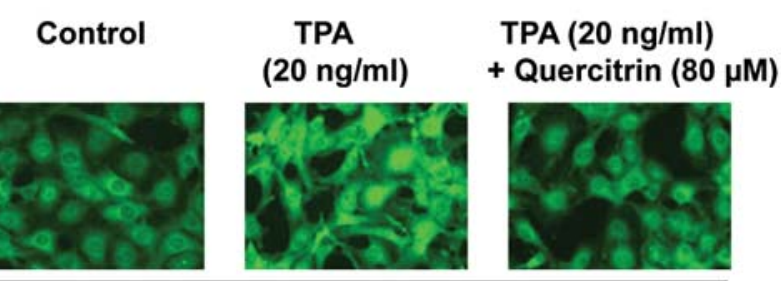

Localization of p65
B

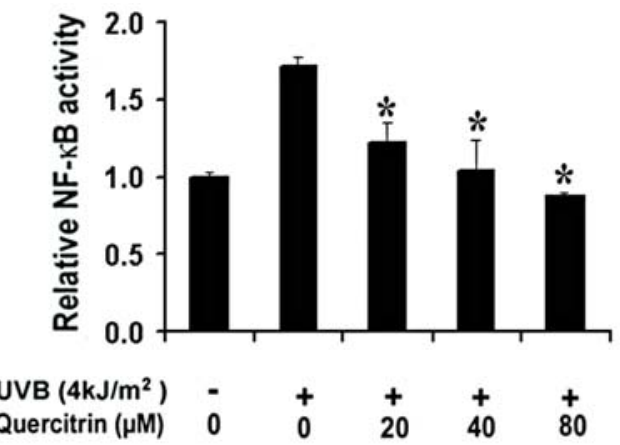

D

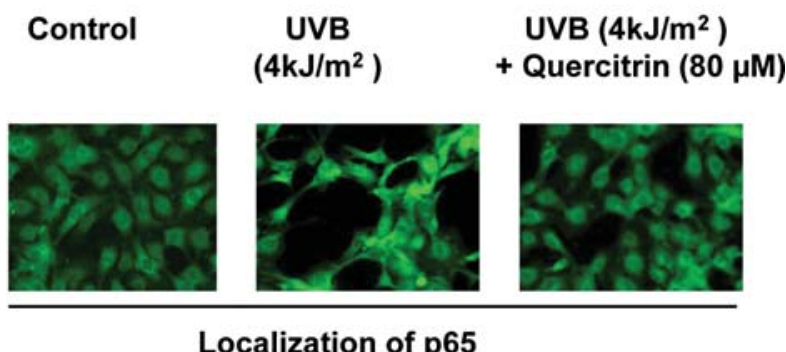

Figure 3. Inhibition of quercitrin on TPA- and UVB-induced NF- $\mathrm{BB}$ activation in vitro. JB6 cells were pretreated with different concentrations of quercitrin for $1 \mathrm{~h}$ and then exposed to $20 \mathrm{ng} / \mathrm{ml}$ of TPA or UVB $\left(4 \mathrm{~kJ} / \mathrm{m}^{2}\right)$ irradiation for $14 \mathrm{~min}\left(\mathrm{~A}\right.$ and B). After culturing the cells at $37^{\circ} \mathrm{C}$ for $48 \mathrm{~h}$, the $\mathrm{NF}-\mathrm{kB}$ activity of the cell extract was measured by the luciferase activity assay. *Significant inhibition of NF- $\kappa \mathrm{B}$ activity when quercitrin was added compared to TPA or UVB radiation treatment alone $(\mathrm{p} \leq 0.05)$ analyzed using t-test (Mann-Whitney Rank Sum Test). Indirect immunofluorescence analysis indicated that pretreatment of the cells with quercitrin significantly blocked TPA- or UVB-induced nuclear translocations of p65 subunit of NF- $\mathrm{kB}$ (C and D).

(Fig. 1B). Means of tail length were calculated for each comet, and the mean values for each data set derived. Means of the comet tail length were then plotted against different treatments. The mean of the comet tail length treated with UVB alone was significantly enhanced compared with negative controls. Quercitrin alone, even at a concentration of $80 \mu \mathrm{M}$, did not induce a significant increase of tail length, but quercitrin displayed a significant suppression in a dose-dependent manner on UVB irradiation-induced tail length (Fig. 1C).

Effects of quercitrin on cell proliferation and viability. To evaluate the cytotoxicity of quercitrin, ECIS and MTT assays were performed. JB6 cells were monitored on the microelectrode with or without quercitrin for $72 \mathrm{~h}$ as real-time changes in resistance by using the ECIS assay. Cells cultured in serumfree medium were used as a negative control. As shown in Fig. 2A, there was no obvious inhibitory effect on proliferation of the cells at $80 \mu \mathrm{M}$ of quercitrin. Similar results were obtained in the MTT assay (Fig. 2B), at a concentration of $80 \mu \mathrm{M}$, quercitrin did not suppress cell proliferation in JB6 cells compared with negative control cells. These results suggest that quercitrin is an effective antioxidant with little cytotoxicity.

Effects of quercitrin on TPA- or UVB-induced NF- $\kappa B$ and $A P-1$ activation. The effects of quercitrin on TPA- and UVBinduced NF- $\kappa \mathrm{B}$ and AP-1 activities were investigated using a reporter gene assay both in vitro and in vivo. Pretreatment of cells with quercitrin significantly inhibited TPA- and UVBinduced NF- $\kappa$ B activation in a dose-dependent manner (Fig. 3A and B). Indirect immunofluorescence analysis indicated that pretreatment of the cells with quercitrin significantly blocked TPA- and UVB-induced nuclear translocations of p65 subunit of NF-кB (Fig. 3C and D).

The effects of quercitrin on TPA- and UVB-induced AP-1 activation were also tested. The results indicated that pretreatment of the cells with various concentrations of quercitrin produced a dose-dependent decrease in AP-1 activation induced by either TPA or UVB irradiation (Fig. 4A and B). Quercitrin treatment also significantly blocked TPA- and UVB-induced nuclear translocations of the c-jun subunit of AP-1 (Fig. 4C and D).

The in vivo effect of quercitrin on TPA-induced AP-1 activity was explored using AP-1-luciferase reporter transgenic mice (Fig. 4E and F). The dorsal skin of the mice was pretreated topically with quercitrin for $30 \mathrm{~min}$ and then exposed to TPA. The luciferase activities were measured on dorsal skin punch biopsy samples. Pretreatment of quercitrin significantly suppressed TPA-induced AP-1 activation at $72 \mathrm{~h}$ (Fig. 4F).

Effect of quercitrin on TPA- or UVB-induced activation of $M A P K s$. Fig. 5A and B show that quercitrin suppressed UVBand TPA-induced phosphorylation of p38, ERK and JNK in a dose-dependent manner. After $24 \mathrm{~h}$ treatment, quercitrin induces GST ARE-luciferase activity increasing significantly at 40 and $80 \mu \mathrm{M}$ (Fig. 5C).

Western blot analysis revealed that the protein levels of Nrf2 in the nucleus were increased following the treatment of cells with $40 \mu \mathrm{M}$ quercitrin for $3 \mathrm{~h}$, whereas $\mathrm{Nrf} 2$ in total cell 
A

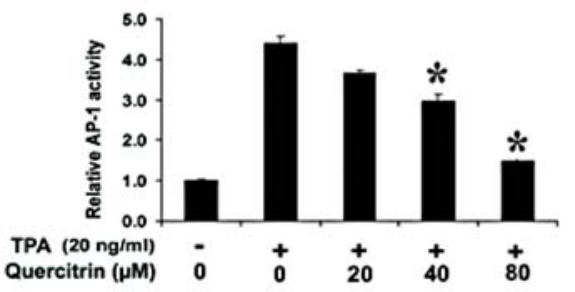

C

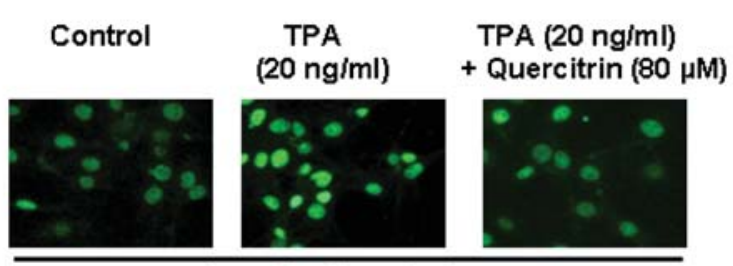

Localization of c-jun

E

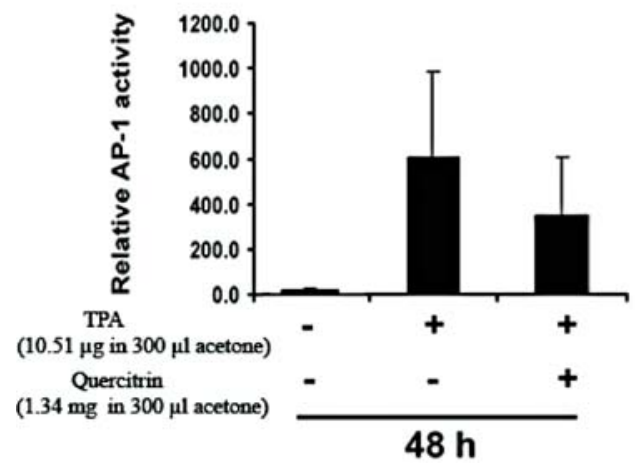

B

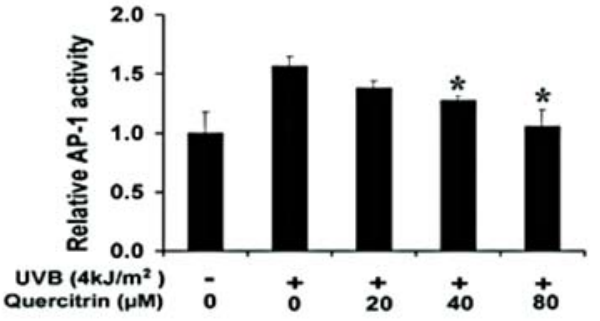

D

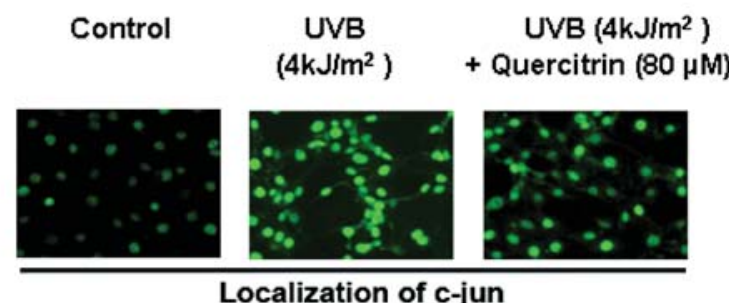

$\mathbf{F}$

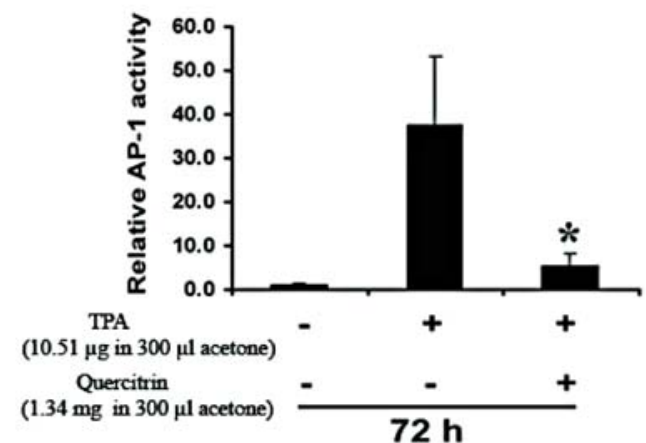

Figure 4. Inhibition of quercitrin on TPA- and/or UVB-induced AP-1 activation in vitro or in vivo. JB6 cells were pretreated with different concentrations of quercitrin for $1 \mathrm{~h}$ and then exposed to $20 \mathrm{ng} / \mathrm{ml}$ of TPA or UVB $\left(4 \mathrm{~kJ} / \mathrm{m}^{2}\right)$ irradiation for $14 \mathrm{~min}$ (A and B). After culturing the cells at $37^{\circ} \mathrm{C}$ for $48 \mathrm{~h}$, the $\mathrm{AP}-1$ activity of the cell extract was measured by the luciferase activity assay. *Significant inhibition of AP-1 activation when quercitrin was added compared to TPA or UVB radiation treatment alone ( $\mathrm{p} \leq 0.05)$ analyzed using t-test (Mann-Whitney Rank Sum Test). Indirect immunofluorescence analysis indicated that pretreatment of the cells with quercitrin significantly blocked TPA- or UVB-induced nuclear translocations of c-jun subunit of AP-1 (C and D). The in vivo inhibition of quercitrin on the AP-1 activity induced by TPA was explored by using AP-1-luciferase reporter transgenic mice as described in Materials and methods. At the end of the experiment ( 48 and $72 \mathrm{~h}$ ), the skin tissues were obtained by a 1.5 -mm biopsy punch (14 mice in control group including 7 males and 7 females, 21 mice in treatment group including 11 males and 10 females). The tissues were lysed in lysis buffer at $4{ }^{\circ} \mathrm{C}$ for $12 \mathrm{~h}$. Luciferase activity of AP-1 was measured (E and F). Results, expressed as means \pm SE, are representative of two independent experiments. ${ }^{*}$ Significant inhibition of AP-1 activation by quercitrin compared to TPA treatment alone analyzed by using t-test (Mann-Whitney Rank Sum Test) (p $\leq 0.05$ ).

lysate remained unchanged (Fig. 5D). Moreover, we found that Nrf2 translocation induced by quercitrin was PI 3-kinasedependent, since LY294002 (an inhibitor of the PI 3-kinase pathway) pretreatment could partially block Nrf2 translocation in JB6 cells (Fig. 5D).

Quercitrin stimulates GST and NQO1 enzymatic activity in JB6 cells. To evaluate the possibility that quercitrin possesses a similar induction of detoxifying enzymes, JB6 cells were incubated with quercitrin for $24 \mathrm{~h}$, and the NQO1 and total GST activities were measured. Quercitrin significantly stimu- lated both GST and NQO1 enzymatic activity in a dosedependent manner (Fig. 6A and B). At concentrations of 40 and $80 \mu \mathrm{M}$ of quercitrin, GST and NQO1 activities were increased by about $100 \%$, respectively.

Quercitrin inhibits TPA-induced JB6 cell transformation. Previous studies have demonstrated that AP-1 and/or NF-кB activation is required in neoplastic transformation and tumorigenesis in JB6 $\mathrm{P}^{+}$cells (35). We thus tested the effect of quercitrin on TPA-induced cell transformation using the soft agar assay. Results shown in Fig. 6C indicate that TPA-induced 
A

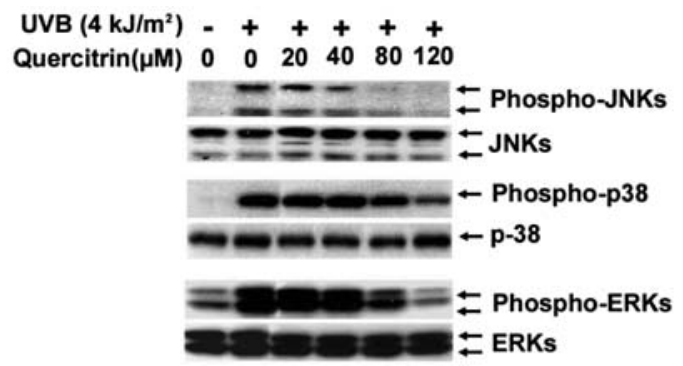

B TPA $(20 \mathrm{ng} / \mathrm{ml})-+++++$

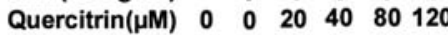

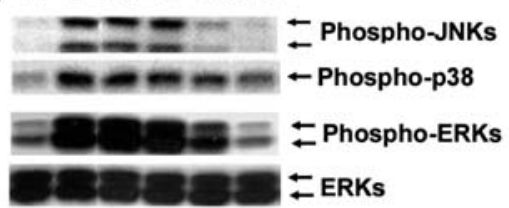

C

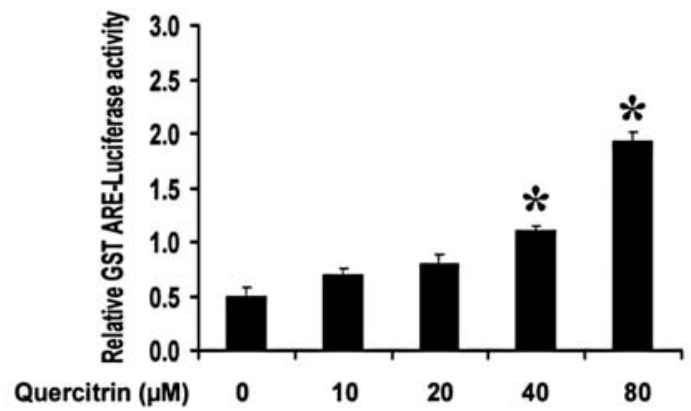

D

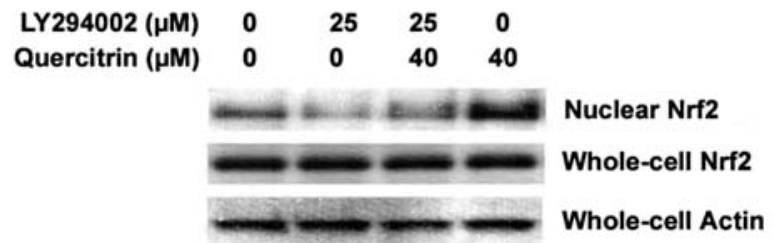

Figure 5. Effects of quercitrin on phosphorylation of MAPKs, GST A1 activation, and Nrf2 nucleus translocation. JB6 cells were pretreated with different concentrations of quercitrin for $1 \mathrm{~h}$ and then were exposed to UVB $\left(4 \mathrm{~kJ} / \mathrm{m}^{2}\right.$, for $\left.14 \mathrm{~min}\right)$ irradiation or TPA (20 $\left.\mathrm{ng} / \mathrm{ml}\right)$. After $12 \mathrm{~h} \mathrm{incubation}$, the phosphorylated and non-phosphorylated JNK, p38 and ERK proteins in the cell lysate were assayed. The phosphorylated proteins and nonphosphorylated proteins were detected, using the same transferred membrane blot following a stripping procedure. The inhibitory effects of quercitrin on UVB- (A) or TPA (B)-induced phosphorylation of JNK, p38 and ERK were detected by Western blot analysis. GST A1 activation induced by quercitrin was conducted with various concentrations of quercitrin for $24 \mathrm{~h}$, and the luciferase activity was measured (C). Results are expressed as means \pm SE of three assay wells. The experiment was repeated three times. "Significant increase in ARE-luciferase activity induced by quercitrin compared with control cells ( $\mathrm{p} \leq 0.05)$ analyzed using t-test (Mann-Whitney Rank Sum Test). JB6 cells either with or without LY294002 pretreatment for 30 min was used in the experiment for the detection of Nrf2 expression. Then, cells were incubated with $40 \mu \mathrm{M}$ quercitrin for $3 \mathrm{~h}$. Nrf2 protein level in the nucleus or in total cell lysate was detected by Western blot analysis (D).

cell transformation was significantly inhibited by quercitrin at concentrations of 40 and $80 \mu \mathrm{M}$.

\section{Discussion}

Chemoprevention, the use of drugs or natural substances to inhibit carcinogenesis, is an important and rapidly evolving aspect of cancer research. It provides a practical approach to identifying potentially useful inhibitors of cancer development. Quercitrin, the glycoside form of quercetin, is a bioflavonoid with antioxidant properties, and exerts anti-inflammatory and antioxidant activities demonstrated by in vitro cell cultures or in vivo animal models $(7,9)$. This study reports molecular evidence for anti-carcinogenic potential for quercitrin. The results from this study suggest that quercitrin displays a similar antioxidant activity as well as ascorbic acid. Quercitrin also inhibited TPA-induced neoplastic transformation and prevented DNA damage induced by UVB irradiation. The mechanistic studies suggest that the possible anti-carcinogenic activity may be due to the inhibitory effects on NF- $\mathrm{B}$ and AP-1-MAPKs signaling and the inductive effects on phase 2 gene activities.

ROS have been known to be associated with many diseases. ROS are associated not only with initiation, but also with promotion and progression in the multistage carcinogenesis mode (36). It has been reported that oxidative stress induces activation of transcription factors and the expression of several oncogenes, including AP-1, NF- $\kappa \mathrm{B}, \mathrm{c}-m y c$, and $\mathrm{c}-f o s$, which enhance cell proliferation (37). Reducing oxidative stress may suppress the proliferation of tumor cells (38). The results of the current study demonstrate that quercitrin can act as an antioxidant as well as ascorbic acid, over the same concentration range in vitro. This suggests that the chemopreventive activity of quercitrin may be due to its antioxidant properties. It has been shown that UVB radiation produces DNA damage directly and indirectly through oxidative stress (39). UVB irradiation, which stimulates ROS generation and causes DNA damage, is known to evoke the emergence of apoptotic cells (40). In this study, the antioxidant properties of quercitrin may contribute to its protective effect against UVB-induced DNA damage.

AP- 1 and NF- $\kappa$ B are transcription factors that have been implicated in a wide range of cell biological events, including cell proliferation, inflammation, differentiation, metastasis, and apoptosis. On the other hand, inhibition of AP-1 and NF- $\kappa \mathrm{B}$ activations by a variety of agents has been shown to reduce neoplastic transformation (25). In vivo studies in transgenic mice indicate that AP-1 transactivation is required for tumor promotion (25). The blockade of TPA-induced cell transformation by quercitrin might be through the inhibition of AP-1 and NF- $\mathrm{-B}$ activity. Therefore, the inhibitory effects of quercitrin on AP-1 and NF- $\kappa \mathrm{B}$ activation noted in this study suggest a potential beneficial role in preventing carcinogenesis.

Although many mechanisms may be involved in the upand down-regulation of AP-1 activity, MAPKs including ERKs, JNKs and p38 kinases are known to be common signaling pathways mediating AP-1 activity (41). Activation of the MAPK pathway is a frequent event in tumorigenesis. MAPKs are activated in response to environmental stresses and growth factors. JNK, p38, and ERK are key molecules 
A

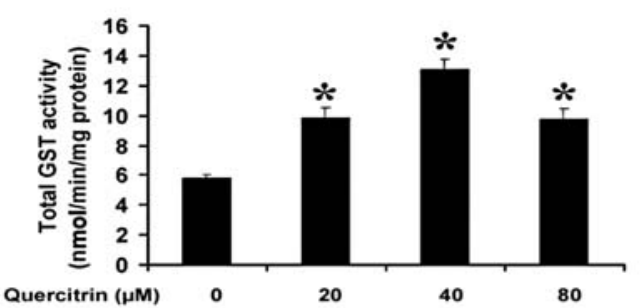

B

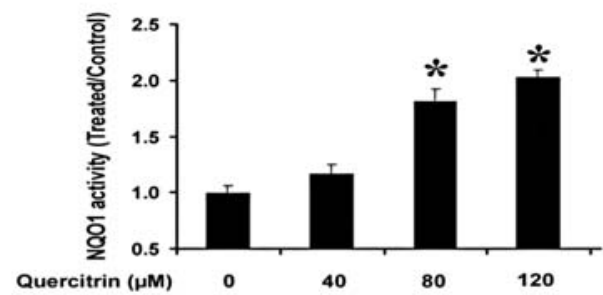

C

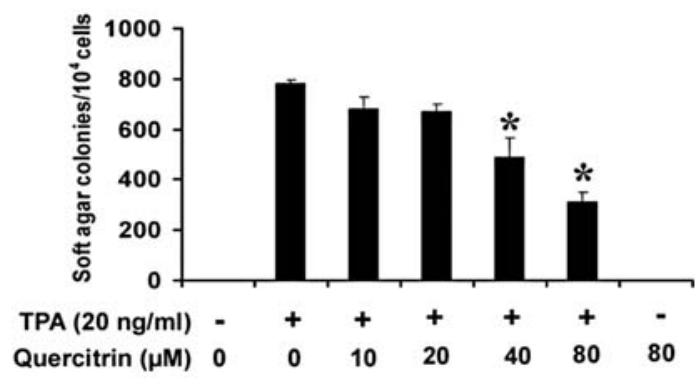

Figure 6. Quercitrin stimulates GST and NQO1 activity and inhibits TPAinduced JB6 cell transformation. JB6 cells were incubated with quercitrin for $24 \mathrm{~h}$. Total GST and NQO1 activity was detected. Total GST activity was expressed as $\mathrm{nmol} / \mathrm{min} / \mathrm{mg}$ protein (A). For NQO1 activity, the values are means $\pm \mathrm{SE}$ and are expressed as ratios of treated over vehicle control (B). The experiment was repeated three times. *Significant induction of total GST or NQO1 activity by quercitrin compared to controls $(\mathrm{p} \leq 0.05)$ analyzed using t-test (Mann-Whitney Rank Sum Test). The effect of quercitrin on TPA-induced cell anchorage-independent transformation was determined as described under Materials and methods. The cell colonies were scored by a computerized image analyzer. The values (mean \pm SE) shown are a representative of two independent experiments performed in triplicate (C). *Significant decrease of soft agar colony formation when quercitrin was added compared to TPA treatment alone $(\mathrm{p} \leq 0.05)$ analyzed using t-test (MannWhitney Rank Sum Test).

activated in response to oxidant injury $(42,43)$. Previous experiments have shown that both UVB and TPA can induce ROS generation in the cells $(44,45)$. In this study, we found that quercitrin could inhibit both UVB- and TPA-induced phosphorylation of JNK, p38 and ERKs. These observations suggest that the inhibitory effects on AP-1 and MAPKs activation with quercitrin may be due partially to its antioxidant properties.

The capacity of cells to maintain homeostasis during oxidative stress resides in activation or induction of protective enzymes. Among them, the induction of detoxification and antioxidant enzymes by natural and synthetic chemopreventive agents serves as a major protective mechanism against carcinogenesis. As a member of bZIP transcription factors, Nrf2 is expressed in a variety of tissues and plays an important role in regulating the expression of these mammalian detoxifying and antioxidant enzymes under oxidative stress. Transcriptional activation of antioxidant genes through an antioxidant response element (ARE) is largely dependent upon Nrf2 (46). The present study indicates that quercitrin could induce GST and NQO1 enzymatic activities, Nrf2 nuclear translocation, as well as GSTA1 ARE-luciferase activation. These results indicate that a possible mechanism of the antioxidant actions of quercitrin may be via induction of phase 2 detoxifying enzymes, such as GST and NQO1.

In conclusion, we have demonstrated that the quercitrin exhibits antioxidant activities in both in vitro and in vivo experiments, which is possibly achieved by the activation of Nrf2 that is critical for the expression of phase 2 antioxidative enzymes. The antioxidant activities of quercitrin may further prevent the activation of MAPKs, AP-1 and NF-кB. These results suggest that quercitrin may function as a potential anticancer agent with little cytotoxicity to normal cells. Thus, quercitrin merits further investigation as a cancer therapeutic and preventive agent in humans. These studies establish a promising area of investigation in understanding the molecular mechanisms responsible for the beneficial effects of polyphenols on human health.

\section{Acknowledgements}

We thank Dr C. Dong for statistical analysis. This research was supported in part by National Institute for Environmental Health Science and National Cancer Institute grants CA119028, CA116697 and ES015375.

\section{References}

1. Bubici C, Papa S, Dean K and Franzoso G: Mutual cross-talk between reactive oxygen species and nuclear factor-kappa $\mathrm{B}$ : molecular basis and biological significance. Oncogene 25: 6731-6748, 2006.

2. Storz P: Reactive oxygen species-mediated mitochondria-tonucleus signaling: a key to aging and radical-caused diseases. Sci STKE 2006: re3, 2006.

3. Halliwell B: Oxidative stress and cancer: have we moved forward? Biochem J 401: 1-11, 2007.

4. Gugliucci A and Stahl AJ: Low density lipoprotein oxidation is inhibited by extracts of Ilex paraguariensis. Biochem Mol Biol Int 35: 47-56, 1995.

5. Nishino H, Murakoshi M, Mou XY, Wada S, Masuda M, Ohsaka Y, Satomi Y and Jinno K: Cancer prevention by phytochemicals. Oncology 69 (Suppl 1): 38-40, 2005.

6. Hollman PC, De Vries JH, van Leeuwen SD, Mengelers MJ and Katan MB: Absorption of dietary quercetin glycosides and quercetin in healthy ileostomy volunteers. Am J Clin Nutr 62: 1276-1282, 1995.

7. Comalada M, Camuesco D, Sierra S, Ballester I, Xaus J, Galvez J and Zarzuelo A: In vivo quercitrin anti-inflammatory effect involves release of quercetin, which inhibits inflammation through down-regulation of the NF-kappaB pathway. Eur J Immunol 35: 584-592, 2005.

8. Gee JM, DuPont MS, Rhodes MJ and Johnson IT: Quercetin glucosides interact with the intestinal glucose transport pathway. Free Radic Biol Med 25: 19-25, 1998.

9. Wagner C, Fachinetto R, Dalla Corte CL, Brito VB, Severo D, De Oliveira Costa Dias G, Morel AF, Nogueira CW and Rocha JB: Quercitrin, a glycoside form of quercetin, prevents lipid peroxidation in vitro. Brain Res 1107: 192-198, 2006.

10. Shen G, Jeong WS, Hu R and Kong AN: Regulation of Nrf2, NF-kappaB, and AP-1 signaling pathways by chemopreventive agents. Antioxid Redox Signal 7: 1648-1663, 2005.

11. Bernstein LR and Colburn NH: AP1/jun function is differentially induced in promotion-sensitive and resistant JB6 cells. Science 244: 566-569, 1989. 
12. Darnell JE Jr: Transcription factors as targets for cancer therapy. Nat Rev Cancer 2: 740-749, 2002.

13. Bode AM and Dong Z: Signal transduction pathways: targets for chemoprevention of skin cancer. Lancet Oncol 1: 181-188, 2000 .

14. Huang C, Ma WY, Young MR, Colburn N and Dong Z: Shortage of mitogen-activated protein kinase is responsible for resistance to AP-1 transactivation and transformation in mouse JB6 cells. Proc Natl Acad Sci USA 95: 156-161, 1998.

15. Itoh K, Chiba T, Takahashi S, Ishii T, Igarashi K, Katoh Y, Oyake T, Hayashi N, Satoh K, Hatayama I, Yamamoto M and Nabeshima Y: An Nrf2/small Maf heterodimer mediates the induction of phase II detoxifying enzyme genes through antioxidant response elements. Biochem Biophys Res Commun 236: 313-322, 1997.

16. Kwak MK, Itoh K, Yamamoto M and Kensler TW: Enhanced expression of the transcription factor Nrf2 by cancer chemopreventive agents: role of antioxidant response element-like sequences in the nrf2 promoter. Mol Cell Biol 22: 2883-2892, 2002.

17. Ramos-Gomez M, Kwak MK, Dolan PM, Itoh K, Yamamoto M, Talalay P and Kensler TW: Sensitivity to carcinogenesis is increased and chemoprotective efficacy of enzyme inducers is lost in nrf2 transcription factor-deficient mice. Proc Natl Acad Sci USA 98: 3410-3415, 2001.

18. Ramos-Gomez M, Dolan PM, Itoh K, Yamamoto M and Kensler TW: Interactive effects of nrf 2 genotype and oltipraz on benzo[a]pyrene-DNA adducts and tumor yield in mice. Carcinogenesis 24: 461-467, 2003.

19. De Gruijl FR and Forbes PD: UV-induced skin cancer in a hairless mouse model. Bioessays 17: 651-660, 1995.

20. Forbes PD: Relevance of animal models of photocarcinogenesis to humans. Photochem Photobiol 63: 357-362, 1996.

21. Dwivedi C, Valluri HB, Guan X and Agarwal R: Chemopreventive effects of alpha-santalol on ultraviolet $\mathrm{B}$ radiationinduced skin tumor development in SKH-1 hairless mice. Carcinogenesis 27: 1917-1922, 2006.

22. Ding M, Lu Y, Bowman L, Huang C, Leonard S, Wang L, Vallyathan V, Castranova V and Shi X: Inhibition of AP-1 and neoplastic transformation by fresh apple peel extract. J Biol Chem 279: 10670-10676, 2004

23. Ding M, Feng R, Wang SY, Bowman L, Lu Y, Qian Y, Castranova V, Jiang $\mathrm{BH}$ and Shi X: Cyanidin-3-glucoside, a natural product derived from blackberry, exhibits chemopreventive and chemotherapeutic activity. J Biol Chem 281: 17359-17368, 2006.

24. Kwak MK, Kensler TW and Casero RA Jr: Induction of phase 2 enzymes by serum oxidized polyamines through activation of Nrf2: effect of the polyamine metabolite acrolein. Biochem Biophys Res Commun 305: 662-670, 2003.

25. Li JJ, Westergaard C, Ghosh P and Colburn NH: Inhibitors of both nuclear factor-kappaB and activator protein-1 activation block the neoplastic transformation response. Cancer Res 57: 3569-3576, 1997.

26. Feng R, Lu Y, Bowman LL, Qian Y, Castranova V and Ding M: Inhibition of activator protein-1, NF-kappaB, and MAPKs and induction of phase 2 detoxifying enzyme activity by chlorogenic acid. J Biol Chem 280: 27888-27895, 2005.

27. Singh NP, McCoy MT, Tice RR and Schneider EL: A simple technique for quantitation of low levels of DNA damage in individual cells. Exp Cell Res 175: 184-191, 1988.

28. Blasiak J, Kowalik J, Malecka-Panas E, Drzewoski J and Wojewodzka M: DNA damage and repair in human lymphocytes exposed to three anticancer platinum drugs. Teratog Carcinog Mutagen 20: 119-131, 2000.
29. Zhao HW, Yin XJ, Frazer D, Barger MW, Siegel PD, Millecchia L, Zhong BZ, Tomblyn S, Stone S, Ma JK, Castranova V and Ma JY: Effects of paving asphalt fume exposure on genotoxic and mutagenic activities in the rat lung. Mutat Res 557: 137-149, 2004.

30. Rincon M and Flavell RA: AP-1 transcriptional activity requires both $\mathrm{T}$-cell receptor-mediated and co-stimulatory signals in primary T lymphocytes. EMBO J 13: 4370-4381, 1994.

31. Huang C, Ma WY, Dawson MI, Rincon M, Flavell RA and Dong Z: Blocking activator protein-1 activity, but not activating retinoic acid response element, is required for the antitumor promotion effect of retinoic acid. Proc Natl Acad Sci USA 94: 5826-5830, 1997.

32. Chen F, Ding M, Lu Y, Leonard SS, Vallyathan V, Castranova V and Shi X: Participation of MAP kinase p38 and IkappaB kinase in chromium (VI)-induced NF-kappaB and AP-1 activation. J Environ Pathol Toxicol Oncol 19: 231-238, 2000.

33. Habig WH, Pabst MJ and Jakoby WB: Glutathione Stransferases. The first enzymatic step in mercapturic acid formation. J Biol Chem 249: 7130-7139, 1974.

34. Colburn NH, Wendel EJ and Abruzzo G: Dissociation of mitogenesis and late-stage promotion of tumor cell phenotype by phorbol esters: mitogen-resistant variants are sensitive to promotion. Proc Natl Acad Sci USA 78: 6912-6916, 1981.

35. Young MR, Li JJ, Rincon M, Flavell RA, Sathyanarayana BK, Hunziker R and Colburn N: Transgenic mice demonstrate AP-1 (activator protein-1) transactivation is required for tumor promotion. Proc Natl Acad Sci USA 96: 9827-9832, 1999.

36. Seifried HE, McDonald SS, Anderson DE, Greenwald P and Milner JA: The antioxidant conundrum in cancer. Cancer Res 63: 4295-4298, 2003

37. Hou DX, Kai K, Li JJ, Lin S, Terahara N, Wakamatsu M, Fujii M, Young MR and Colburn N: Anthocyanidins inhibit activator protein 1 activity and cell transformation: structure-activity relationship and molecular mechanisms. Carcinogenesis 25: 29-36, 2004.

38. Crosby LM, Hyder KS, DeAngelo AB, Kepler TB, Gaskill B, Benavides GR, Yoon L and Morgan KT: Morphologic analysis correlates with gene expression changes in cultured F344 rat mesothelial cells. Toxicol Appl Pharmacol 169: 205-221, 2000.

39. Ichihashi M, Ueda M, Budiyanto A, Bito T, Oka M, Fukunaga M, Tsuru K and Horikawa T: UV-induced skin damage. Toxicology 189: 21-39, 2003

40. Barzilai AA and Yamamoto KK-I: DNA damage responses to oxidative stress. DNA repair 3: 1109-1115, 2004.

41. Karin M: The regulation of AP-1 activity by mitogen-activated protein kinases. J Biol Chem 270: 16483-16486, 1995.

42. Ogura $\mathrm{M}$ and Kitamura M: Oxidant stress incites spreading of macrophages via extracellular signal-regulated kinases and p38 mitogen-activated protein kinase. J Immunol 61: 3569-3574, 1998.

43. Carvalho H, Evelson P, Sigaud S and Gonzalez-Flecha B: Mitogen-activated protein kinases modulate $\mathrm{H}(2) \mathrm{O}(2)$-induced apoptosis in primary rat alveolar epithelial cells. J Cell Biochem 92: 502-513, 2004

44. Karin M: Mitogen-activated protein kinase cascades as regulators of stress responses. Ann N Y Acad Sci 851: 139-146, 1998.

45. Chang H, Oehrl W, Elsner P and Thiele JJ: The role of $\mathrm{H}_{2} \mathrm{O}_{2}$ as a mediator of UVB-induced apoptosis in keratinocytes. Free Radic Res 37: 655-663, 2003.

46. Kang KW, Lee SJ and Kim SG: Molecular mechanism of nrf2 activation by oxidative stress. Antioxid Redox Signal 7: 1664-1673, 2005. 